\title{
FUS pathology defines the majority of tau- and TDP-43-negative frontotemporal lobar degeneration
}

\author{
Hazel Urwin • Keith A. Josephs • Jonathan D. Rohrer • Ian R. Mackenzie • Manuela Neumann • \\ Astrid Authier · Harro Seelaar · John C. Van Swieten · Jeremy M. Brown · Peter Johannsen • \\ Jorgen E. Nielsen • Ida E. Holm • The FReJA Consortium • Dennis W. Dickson - Rosa Rademakers • \\ Neill R. Graff-Radford · Joseph E. Parisi · Ronald C. Petersen · Kimmo J. Hatanpaa • Charles L. White III • \\ Myron F. Weiner · Felix Geser • Vivianna M. Van Deerlin · John Q. Trojanowski - Bruce L. Miller • \\ William W. Seeley $\cdot$ Julie van der Zee $\cdot$ Samir Kumar-Singh $\cdot$ Sebastiaan Engelborghs $•$ \\ Peter P. De Deyn • Christine Van Broeckhoven • Eileen H. Bigio · Han-Xiang Deng • Glenda M. Halliday • \\ Jillian J. Kril • David G. Munoz • David M. Mann - Stuart M. Pickering-Brown • Valerie Doodeman • \\ Gary Adamson - Shabnam Ghazi-Noori - Elizabeth M. C. Fisher · Janice L. Holton - Tamas Revesz • \\ Martin N. Rossor $\cdot$ John Collinge $\cdot$ Simon Mead $\cdot$ Adrian M. Isaacs
}

Received: 11 January 2010/Revised: 20 April 2010/Accepted: 8 May 2010/Published online: 20 May 2010

(C) The Author(s) 2010. This article is published with open access at Springerlink.com

\begin{abstract}
Through an international consortium, we have collected 37 tau- and TAR DNA-binding protein 43 (TDP43)-negative frontotemporal lobar degeneration (FTLD) cases, and present here the first comprehensive analysis of
\end{abstract}

Members of the FReJA consortium are listed in the Appendix.

H. Urwin · A. Authier · G. Adamson - S. Ghazi-Noori ·

J. Collinge $\cdot$ S. Mead $\cdot$ A. M. Isaacs $(\square)$

MRC Prion Unit, UCL Institute of Neurology,

Queen Square, London WC1N 3BG, UK

e-mail: a.isaacs@prion.ucl.ac.uk

J. D. Rohrer · M. N. Rossor

Dementia Research Centre, UCL Institute of Neurology,

Queen Square, London WC1N 3BG, UK

E. M. C. Fisher - J. Collinge

Department of Neurodegenerative Disease, UCL Institute

of Neurology, Queen Square, London WC1N 3BG, UK

\section{J. L. Holton · T. Revesz}

Department of Neuropathology, UCL Institute of Neurology,

Queen Square, London WC1N 3BG, UK

K. A. Josephs $(\varangle) \cdot$ R. C. Petersen

Department of Neurology, Mayo Clinic,

Rochester, MN, USA

e-mail: Josephs.Keith@mayo.edu

\section{J. E. Parisi}

Department of Laboratory Medicine and Pathology,

Mayo Clinic, Rochester, MN, USA these cases in terms of neuropathology, genetics, demographics and clinical data. 92\% (34/37) had fused in sarcoma (FUS) protein pathology, indicating that FTLD-FUS is an important FTLD subtype. This FTLD-FUS collection specifically focussed on aFTLD-U cases, one of three recently defined subtypes of FTLD-FUS. The aFTLD-U subtype of

\section{R. Mackenzie}

Department of Pathology and Laboratory Medicine,

Vancouver General Hospital, University of British Columbia,

Vancouver, BC, Canada

\section{Neumann}

Institute of Neuropathology, University Hospital of Zurich,

Zurich, Switzerland

H. Seelaar · J. C. Van Swieten

Department of Neurology, Erasmus University Medical Center Rotterdam, Rotterdam, The Netherlands

\section{J. M. Brown}

Department of Neurology, Addenbrooke's Hospital,

Cambridge, UK

\section{P. Johannsen · J. E. Nielsen}

Memory Disorders Research Unit, Department of Neurology,

Copenhagen University Hospital, Rigshospitalet,

Copenhagen, Denmark

\section{J. E. Nielsen}

Department of Cellular and Molecular Medicine,

Section of Neurogenetics, The Panum Institute,

University of Copenhagen, Copenhagen, Denmark 
FTLD-FUS is characterised clinically by behavioural variant frontotemporal dementia (bvFTD) and has a particularly young age of onset with a mean of 41 years. Further, this subtype had a high prevalence of psychotic symptoms (36\% of cases) and low prevalence of motor symptoms (3\% of cases). We did not find FUS mutations in any aFTLD-U case. To date, the only subtype of cases reported to have ubiquitin-positive but tau-, TDP-43- and FUS-negative pathology, termed FTLD-UPS, is the result of charged multivesicular body protein 2B gene (CHMP2B) mutation. We identified three FTLD-UPS cases, which are negative for CHMP2B mutation, suggesting that the full complement of FTLD pathologies is yet to be elucidated.

Keywords FTLD $\cdot$ FUS $\cdot$ FTLD-UPS $\cdot$ Frontotemporal · FTD

\section{Abbreviations}

bvFTD Behavioural variant FTD

CHMP2B Charged multivesicular body protein 2B

\section{E. Holm}

Department of Pathology, Randers Hospital,

Randers and Laboratory for Experimental Neuropathology,

Danish Neuroscience Center, Aarhus University Hospital,

Aarhus, Denmark

D. W. Dickson · R. Rademakers · N. R. Graff-Radford Department of Neuroscience, Mayo Clinic, Jacksonville, FL, USA

K. J. Hatanpaa · C. L. White III

Department of Pathology, University of Texas Southwestern Medical School, Dallas, TX, USA

\section{F. Weiner}

Departments of Psychiatry and Neurology, University of Texas Southwestern Medical School, Dallas, TX, USA

F. Geser · V. M. Van Deerlin · J. Q. Trojanowski Center for Neurodegenerative Disease Research, Department of Pathology and Laboratory Medicine, University of Pennsylvania School of Medicine, Philadelphia, USA

B. L. Miller · W. W. Seeley

UCSF Department of Neurology, Memory and Aging Center, San Francisco, CA, USA

J. van der Zee - S. Kumar-Singh · C. Van Broeckhoven VIB Department of Molecular Genetics, Neurodegenerative Brain Diseases Group, Antwerpen, Belgium

J. van der Zee $\cdot$ S. Kumar-Singh $\cdot$ S. Engelborghs $\cdot$

P. P. De Deyn - C. Van Broeckhoven

Institute Born-Bunge, University of Antwerp,

Antwerpen, Belgium

S. Engelborghs · P. P. De Deyn

Department of Neurology, Memory Clinic, ZNA Middelheim, Antwerpen, Belgium
FTD Frontotemporal dementia

FTD-3 FTD linked to chromosome 3

FTLD Frontotemporal lobar degeneration

FTLD-IF Frontotemporal lobar degeneration with intermediate filament positive inclusions

FTLD-ni Frontotemporal lobar degeneration with no inclusions

FTLD-TDP Frontotemporal lobar degeneration with TDP-43 positive inclusions

FTLD-UPS Frontotemporal dementia with ubiquitin positive, TDP-43 negative inclusions

GRN Progranulin

MAPT Microtubule associated protein tau

NCI Neuronal cytoplasmic inclusion

NII Neuronal intranuclear inclusion

PPA Primary progressive aphasia

TDP-43 Transactive response binding protein of $43 \mathrm{kDa}$

VCP Valosin containing protein

E. H. Bigio

Department of Pathology, Feinberg School of Medicine, Northwestern University, Chicago, IL, USA

H.-X. Deng

Department of Neurology and Clinical Neurosciences, Feinberg School of Medicine, Northwestern University, Chicago, IL, USA

G. M. Halliday

Prince of Wales Medical Research Institute,

University of New South Wales,

Sydney, NSW, Australia

J. J. Kril

Disciplines of Medicine and Pathology, University of Sydney, Sydney, NSW, Australia

D. G. Munoz

Department of Pathology, Saint Michael's Hospital, University of Toronto, Toronto, ON, Canada

D. M. Mann

Clinical Neuroscience Research Group, School of Translational Medicine, Greater Manchester Neurosciences Centre,

University of Manchester, Salford, UK

S. M. Pickering-Brown

Clinical Neurosciences Research Group, Faculty of Human and Medical Sciences, University of Manchester,

Oxford Road, Manchester M13 9PT, UK

V. Doodeman

Department of Clinical Genetics, VU University Medical Center, Amsterdam, The Netherlands 


\section{Introduction}

Frontotemporal lobar degeneration (FTLD) describes a group of diseases characterised by bilateral, often asymmetric, atrophy of the frontal and anterior temporal lobes. Frontotemporal dementia (FTD), also termed behavioural variant FTD (bvFTD), is the most common clinical manifestation, but FTLD can also cause the language disorders progressive non-fluent aphasia (PNFA) and semantic dementia (SD), collectively known as primary progressive aphasia (PPA). The clinical presentation is related to the distribution of pathology in the frontal and temporal lobes. Despite gross pathological similarities, FTLD comprises a clinically, genetically, and neuropathologically heterogeneous collection of disorders.

A family history of a similar disease has been reported in $25-40 \%$ of FTLD cases [6, 44, 50], although this estimate is much lower in some populations [17]. FTLDcausing mutations have been found in the microtubuleassociated protein tau (MAPT) [16], progranulin $(G R N)[1,7]$ and charged multivesicular body protein $2 \mathrm{~B}(C H M P 2 B)$ genes [49]. Mutations in valosin-containing protein (VCP) cause inclusion body myopathy and Paget disease of bone with frontotemporal dementia, in which $20-100 \%$ of patients can develop FTD [10, 53, 56]. GRN mutations account for approximately $10 \%$ of FTLD cases $[2,7-9]$ and MAPT up to $10 \%$ depending on the population studied [15, 41, 48]; while mutations in $C H M P 2 B$ are a much rarer cause of FTLD, having been reported in one Danish family termed frontotemporal dementia linked to chromosome 3 (FTD-3) $[25,49,52]$ and one unrelated Belgian familial FTLD patient [54].

Up to $40 \%$ of FTLD cases, including all MAPT mutation cases, have tau pathology [48] (FTLD-tau); while over $50 \%$ have neuronal inclusions, which are immunoreactive for ubiquitin in the absence of abnormal tau, $\alpha$-synuclein, or amyloid deposition [20]. In the majority of tau-negative cases, the major ubiquitinated protein is the TAR DNAbinding protein 43 (TDP-43) [11, 39], and these are designated FTLD-TDP [30]. FTLD-TDP can be further classified into neuropathological subtypes depending on the distribution, morphology and precise cellular location of inclusions [28, 45].

Recent studies report that 6-20\% of tau-negative FTLD cases have ubiquitinated inclusions which are TDP-43 negative [12, 21, 29, 42]. Ubiquitin positive, tau and TDP43 negative cases include those with neuronal intermediate filament- and $\alpha$-internexin-positive inclusions [5, 19], termed NIFID, and basophilic inclusion body disease (BIBD) $[35,58]$. Distinct from these are a subset of FTLD cases termed atypical FTLD-U (aFTLD-U), which do not have intermediate filament positive or basophilic inclusions, but are characterised by unusual curved or twisted neuronal intranuclear ubiquitin positive inclusions, as well as cytoplasmic inclusions [29, 42]. The recent finding of FUS (fused in sarcoma) protein pathology in aFTLD-U cases [37] and subsequently in NIFID and BIBD cases $[34,38]$ has led to further reorganisation of FTLD classification [31]: aFTLD-U, NIFID and BIBD are now considered three distinct subtypes of FTLD-FUS, the collective term for FTLD cases with FUS pathology. Cases with ubiquitinated inclusions that are negative for tau, TDP-43 and FUS are termed FTLD-UPS [30]; this includes FTLD cases caused by $C H M P 2 B$ mutations [13, 14].

FUS pathology was first described in familial ALS cases following the discovery of causative mutations in the FUS gene $[23,55]$. FUS is a multifunctional DNA- and RNAbinding protein, sharing functional homology with TDP-43 [24]. FUS pathology has also been found in polyglutamine expansion diseases including Huntington's disease, suggesting a broad spectrum of FUS proteinopathies [34, 38, 57]. However, FUS pathology was not found in FTD-3, a major subtype of FTLD-UPS [14].

A minority of cases do not have tau, TDP-43, FUS or ubiquitinated inclusions and these have been termed FTLD with no inclusions (FTLD-ni, previously dementia lacking distinctive histopathology, or DLDH) [30]. Increasingly sensitive immunostaining protocols have led to most FTLDni cases being reclassified [20, 26, 32]; however, a small group remain negative for characterised inclusions despite the use of updated ubiquitin immunohistochemistry.

Here, we report, through a major international collaboration, the first comprehensive collection of the aFTLD-U subtype of FTLD-FUS and describe their clinical and demographic features.

\section{Materials and methods}

\section{Cases}

A total of 37 cases with ubiquitin-positive but tau- and TDP-43-negative inclusions were evaluated from 12 academic research centres. In each centre, clinical information was acquired from case notes by a neurologist with expertise in neurodegenerative diseases. Standard neurological and cognitive assessments were used to ascertain the presence of behavioural, cognitive and motor abnormalities. All centres followed consensus clinical criteria for FTLD diagnosis [33, 36], and were asked to supply presenting symptoms for each patient and the final clinical diagnosis that had been rendered by the evaluating neurologist. These data were collated and then reviewed by an expert in FTLD (K.A.J.) to ensure consistency in diagnosis among the different centres. BIBD and NIFID cases were specifically excluded in order to focus on a specific subtype 
of FTLD-FUS. Twenty-three cases for which DNA was available (21 FTLD-FUS and 2 FTLD-UPS) were screened for $C H M P 2 B$ mutations. Fifteen FTLD-FUS cases were screened for FUS mutations and a further six have been reported previously as FUS mutation negative [37]. Patients were considered to have a family history if a first- or seconddegree relative had dementia. This study was approved by the UCL Institute of Neurology and National Hospital for Neurology and Neurosurgery Local Research Ethics Committee.

\section{Histopathology}

All cases were stained for TDP-43, ubiquitin and $\alpha$-internexin or neurofilament proteins according to local protocols at each centre [2, 12, 21, 27, 29, 39, 40, 42, 47, 53]. Experienced neuropathologists in each centre analysed the sections to give the neuropathological diagnosis. FUS staining was subsequently performed on frontal cortex and hippocampus for all cases. As previously described, FUS staining is sensitive to length of fixation [37]. Therefore, at least two antibodies (Sigma HPA008784 and Bethyl Laboratories A300-302A) were used for all cases examined and antibody concentrations optimised for each case by ensuring physiological FUS staining was visible, as recommended in the original description of FTLD-FUS [37]. To further ensure inter-centre reliability 26 cases, including the three remaining FTLD-UPS cases, were stained in one of two laboratories which first reported FTLD-FUS (IRM or MN).

\section{Genetic analysis}

Genomic DNA was extracted from brain tissue using standard phenol-chloroform extraction, or DNA extracted from brain or blood was directly provided by the contributor. The entire open reading frame and exon-intron boundaries of $C H M P 2 B$ and $F U S$ were sequenced, except for three cases in which FUS exons 14 and 15 only were sequenced. Primers and conditions for $C H M P 2 B$ sequencing have been described previously [49]; conditions for FUS sequencing are available on request. Sequences were analysed using the SeqScape software Version 2.5 (Applied Biosystems, Foster City, CA, USA).

\section{Results}

Neuropathology

A total of 37 ubiquitin-positive, tau- and TDP-43-negative cases were examined. 92\% (34/37) of cases were characterised by neuronal cytoplasmic and intranuclear inclusions (NIIs) which were immunoreactive for FUS, corresponding to the aFTLD-U subtype of FTLD-FUS. The NIIs were as previously described, having an unusual morphology, which can be long and straight, curved or twisted [29, 42]. Striatal degeneration was present in $100 \%$ (27/27) of aFTLD-U cases and hippocampal sclerosis was present in $97 \%$ (29/30) of cases. 8\% (3/37) were characterised by ubiquitin-positive neuronal cytoplasmic inclusions (NCIs) which were FUS-negative, i.e. FTLD-UPS.

Genetics

Sequencing of the $C H M P 2 B$ gene in all cases for which DNA was available revealed no further coding mutations. Two synonymous coding variants were identified in three FTLD-FUS cases: c.27C $>$ T, p.Thr9Thr and c.372A $>$ C, p.Thr124Thr. These two variants were each observed in the heterozygous state but always together, suggesting they could be in linkage disequilibrium. None of these variants has been previously reported, but as they do not lead to an amino acid change, they are unlikely to be pathogenic. Therefore, $C H M P 2 B$ mutation-positive cases comprise a distinct genetic subgroup of FTLD-UPS. No mutations were identified in FUS in any case.

Demographics

Onset

Age at onset data was available for 33 aFTLD-U cases. The mean age of onset was 41.2 years (standard deviation 9.3 years). The three FTLD-UPS cases had a mean age of onset of 50.3 years (standard deviation 4 years).

\section{Disease duration}

Disease duration data were available for 33 aFTLD-U cases. Mean disease duration was 7.7 years (standard deviation 3.2 years). Disease duration data were available for only two of the three FTLD-UPS cases and were 4 and 11 years, respectively.

Sex

Of the aFTLD-U cases, 47\% (16/34) were female and all three FTLD-UPS cases were female.

Family history

One aFTLD-U case $(3 \%, 1 / 34)$ had a family history and $2 / 3$ of the FTLD-UPS cases had positive family histories.

Clinical features

The clinical features of several aFTLD-U cases have previously been reported $[21,29,42,46]$ and analysed together, 
Table 1 Clinical symptoms in aFTLD-U cases

\begin{tabular}{|c|c|c|c|c|c|c|c|c|c|c|c|c|}
\hline \multirow[t]{2}{*}{ ID } & \multirow[t]{2}{*}{ Sex } & \multirow[t]{2}{*}{ Diagnosis } & \multicolumn{5}{|c|}{ Behavioural/personality } & \multicolumn{2}{|l|}{ Psychiatric } & \multirow{2}{*}{$\begin{array}{l}\text { Cognitive } \\
\text { Aphasia }\end{array}$} & \multicolumn{2}{|l|}{ Motor } \\
\hline & & & Apathy & Disinh & $\begin{array}{l}\text { Abnormal } \\
\text { eating }\end{array}$ & Compulsions & $\begin{array}{l}\text { Inappropriate } \\
\text { sexual }\end{array}$ & Delusions & Hallucinations & & Parkinsonism & MND \\
\hline UBC1 & $\mathrm{F}$ & bvFTD & 1 & 1 & 1 & 1 & 0 & 0 & 0 & 0 & 0 & 0 \\
\hline UBC2 & $\mathrm{F}$ & bvFTD & 1 & 0 & 0 & 0 & 1 & 1 & 0 & 0 & 0 & 0 \\
\hline UBC3 & $\mathrm{F}$ & bvFTD & 1 & 1 & 1 & 0 & 1 & 0 & 0 & 0 & 0 & 0 \\
\hline UBC4 & $\mathrm{F}$ & bvFTD & 1 & 1 & 1 & 0 & 0 & 0 & 0 & 0 & 0 & 0 \\
\hline UBC5 & M & bvFTD & 1 & 1 & 1 & 0 & 1 & 1 & 0 & 0 & 0 & 0 \\
\hline UBC6 & $\mathrm{F}$ & bvFTD & 1 & 1 & 0 & 0 & 0 & 0 & 1 & 0 & 0 & 0 \\
\hline MUC1 & M & Dem & NA & NA & NA & NA & NA & NA & NA & NA & NA & NA \\
\hline MUC2 & $\mathrm{F}$ & bvFTD & 1 & 1 & 0 & 0 & NA & NA & NA & 1 & 0 & 0 \\
\hline MUC3 & $\mathrm{F}$ & Dem & NA & 1 & NA & NA & NA & NA & NA & NA & NA & NA \\
\hline MUC4 & M & bvFTD & 1 & 1 & 1 & 1 & NA & NA & NA & 1 & 0 & 0 \\
\hline MUC5 & $\mathrm{F}$ & bvFTD & 0 & 1 & 1 & 0 & NA & NA & NA & 1 & 0 & 0 \\
\hline MUC6 & M & bvFTD & 1 & 1 & NA & NA & NA & NA & NA & NA & NA & NA \\
\hline MUC7 & F & bvFTD & 1 & 1 & 1 & 0 & 0 & 0 & 0 & 0 & 0 & 0 \\
\hline MUC8 & M & bvFTD & NA & 1 & NA & NA & NA & NA & NA & NA & NA & NA \\
\hline MUC9 & M & bvFTD & 0 & 1 & 1 & 1 & NA & NA & NA & 0 & 0 & $0^{\mathrm{a}}$ \\
\hline UR1 & M & bvFTD & 1 & 1 & 1 & 1 & 1 & 0 & 1 & 0 & 0 & 0 \\
\hline UR2 & $\mathrm{F}$ & bvFTD & 1 & 1 & 1 & 0 & 1 & 0 & 0 & 0 & 0 & 0 \\
\hline UR3 & $\mathrm{F}$ & bvFTD & 1 & NA & 1 & 1 & 0 & 1 & 0 & 0 & 0 & 0 \\
\hline UR4 & $\mathrm{F}$ & bvFTD & 1 & 1 & 0 & 1 & 0 & 0 & 0 & 0 & 0 & 0 \\
\hline UT1 & M & bvFTD & NA & 1 & NA & NA & NA & 1 & 0 & 0 & 0 & 0 \\
\hline UTSW1 & M & bvFTD & 1 & 1 & 1 & 1 & 1 & 0 & 0 & 1 & 0 & 0 \\
\hline NWU1 & M & bvFTD & 0 & 1 & 1 & 1 & 1 & 0 & 0 & 0 & 0 & 0 \\
\hline NWU2 & $\mathrm{F}$ & bvFTD & 1 & 1 & 1 & 1 & 1 & 0 & 0 & 1 & 0 & 0 \\
\hline UP1 & $\mathrm{F}$ & bvFTD & 1 & 1 & 1 & 1 & 0 & NA & NA & 0 & 0 & 0 \\
\hline UP2 & M & bvFTD & 1 & 0 & 1 & 1 & 0 & NA & NA & 0 & 0 & 0 \\
\hline UP3 & M & bvFTD & 1 & 1 & NA & 1 & 0 & NA & NA & 0 & 0 & 0 \\
\hline UNSW1 & $\mathrm{F}$ & bvFTD & NA & 1 & NA & 1 & NA & 0 & 0 & 1 & 1 & 0 \\
\hline UNSW2 & M & bvFTD & NA & 1 & 1 & 0 & 0 & 0 & 0 & 1 & 0 & 0 \\
\hline $\mathrm{MC} 1$ & M & bvFTD & 0 & 1 & 1 & 1 & 1 & 0 & 1 & 0 & 0 & 0 \\
\hline MC2 & F & bvFTD & 0 & 1 & NA & 1 & 1 & NA & NA & 0 & 0 & 0 \\
\hline MC3 & M & bvFTD & 0 & 1 & 1 & 1 & 1 & 0 & 0 & 0 & 0 & 0 \\
\hline MC4 & $\mathrm{M}$ & bvFTD & 1 & 0 & 0 & 1 & 0 & 0 & 0 & 0 & 0 & 0 \\
\hline MC5 & M & bvFTD & 0 & 1 & 1 & 0 & 1 & 0 & 0 & 0 & 0 & 0 \\
\hline \multirow[t]{2}{*}{ UCL1 } & M & bvFTD & NA & 1 & 1 & NA & NA & 0 & 1 & NA & 0 & 0 \\
\hline & & $\begin{array}{l}\% \text { with } \\
\text { symptom }\end{array}$ & 74 & 91 & 81 & 61 & 52 & 18 & 18 & 24 & 3 & 0 \\
\hline
\end{tabular}

Cases of aFTLD-U were scored for presence of the symptoms indicated

0 absent, 1 present, NA information not available, bvFTD behavioural variant FTD, Dem unspecified dementia, Disinh disinhibition

${ }^{\text {a }}$ One patient exhibited tongue fasciculation, dysphagia and muscle hypotonia but there was insufficient evidence to diagnose MND

these cases form a clinically homogeneous group. 94\% (32/ 34) of aFTLD-U patients received an initial diagnosis of bvFTD (Table 1). The other two patients, for whom there was little clinical information available, were described as having 'unspecified dementia'. Patients were typically described as showing a decline in social conduct, selfneglect and disinhibition, with aggression as a common feature. Inappropriate sexual behaviour was widely reported, in $52 \%$ of cases $(12 / 23)$ (Table 1). Dietary changes, most commonly overeating, were observed in $81 \%$ of cases (21/26) with hyperorality a feature of several.

Strikingly, psychotic symptoms, either hallucinations or delusions, were observed in $36 \%$ of aFTLD-U patients $(8 / 22)$, and not comorbid in any case. Motor symptoms 
were infrequent and when present, they were typically limited to mild rigidity or intermittent hyperkinesias. Only one patient $(1 / 30,3 \%)$ showed classical parkinsonism.

The three FTLD-UPS cases all had an initial diagnosis of bvFTD. Very little clinical information was available, but apathy was common to two of these cases as was parkinsonism.

\section{Discussion}

This study describes the first comprehensive collection of the aFTLD-U subtype of FTLD-FUS. We show that aFTLD-U has a distinct clinical phenotype characterised by the behavioural variant FTD syndrome, a young onset of disease, a high prevalence of psychotic symptoms and a low prevalence of motor symptoms. FUS pathology accounted for $92 \%$ of cases with ubiquitin-positive, tauand TDP-43-negative FTLD showing that it defines the vast majority of such cases. However, we identified three FTLD-UPS cases without CHMP2B mutation showing that while such cases are rare, the FTLD-UPS classification has not been completely subsumed by CHMP2B mutation cases or FTLD-FUS.

Of all of the FTLD subtypes, bvFTD is pathologically the most heterogeneous making it difficult to predict the underlying pathology from clinical features in life. This cohort similarly has an overlapping range of symptoms with other sporadic and genetic causes of bvFTD. However, psychotic symptoms are rarely described in other cases of bvFTD [22], and the presence of delusions and hallucinations in a substantial proportion of this cohort may help to distinguish them from other patients. The very low frequency of motor symptoms may also help define this group of patients.

The mean age of onset of 41.2 years for the aFTLD-U cases is much lower than that of a previously reported sporadic FTLD cohort (60.5 years) [4], and therefore, may help distinguish them from other sporadic FTLD cases. 15/ 34 aFTLD-U cases came from two contributing centres, therefore, it is possible that the results have been biassed by these cases, which were previously reported to have a low age of onset [29, 42]. However, the age of onset of these cases is not significantly different from the other 19 cases in the study ( $t$ test, ns). Furthermore, psychotic symptoms are evenly distributed between cases from these two centres $(3 / 7,42 \%)$ and cases from other centres $(5 / 15,33 \%)$ (Fisher's exact test, ns).

Only one aFTLD-U case $(3 \%, 1 / 34)$ had a positive family history for FTD: this patient was one of nine siblings, and had one brother who was diagnosed clinically with 'Pick's disease' at 61 years of age and died at 64 years of age without autopsy. Another brother was reported to show 'cognitive changes' at the age of 64 years.
The patient was negative for FUS mutation, suggesting that there may be other genetic causes of FTLD-FUS. While aFTLD-U cases have a distinctive and consistent clinicopathological phenotype, FTLD appears to occur sporadically in the majority of cases. Of the three FTLD-UPS cases, two had a family history, and one had at least two relatives affected with the same disease [43]. These cases were negative for CHMP2B mutations, which suggests other genetic causes of FTLD-UPS and the possibility of at least one other unidentified ubiquitinated protein associated with FTLD. No gender bias was found in any of the groups studied. A female preponderance was previously reported in an analysis of a subset of aFTLD-U cases [29]; however, this was not confirmed in wider analysis.

It has recently been shown that two rare subtypes of FTLD, NIFID and BIBD have extensive FUS pathology [34, 38]. We did not include NIFID and BIBD cases in this study as they have been described to have distinct clinical features to aFTLD-U cases, particularly prominent motor symptoms $[3,18,19,34,51,58]$. In order to allow comparison of FTLD-FUS to other FTLD cases, we focussed on one subtype of FTLD-FUS (aFTLD-U), as it is possible that FTLD-FUS comprises a clinically heterogeneous group. However, now that NIFID, BIBD and aFTLD-U have been shown to have a common underlying pathology, it will be interesting to directly compare these different FUS entities in future studies. FUS pathology is also found in polyglutamine expansion diseases including Huntington's disease [57], showing that it is not limited to the FTLD-MND spectrum of diseases. This is similar to tau and TDP-43 pathology, which are pathological hallmarks of different FTLD subtypes but are also observed in a wide range of other neurodegenerative diseases. Within the clinical syndrome of FTLD, FUS pathology will be an extremely important tool for the classification of cases which are tauand TDP-43- negative, and wider analysis of FTLD-FUS cases may reveal further subtypes.

In conclusion, the vast majority of cases with tau- and TDP-43 negative inclusions have FUS pathology, suggesting that FTLD-FUS is an important FTLD subtype. The opportunity to analyse a large series of aFTLD-U cases has only been possible through a large multi-centre collaboration, with all centres contributing a relatively small number of cases. This collaborative effort has provided new insights into the genetic and clinicopathological spectrum of FTLD-FUS and FTLD-UPS.

Conflict of interest statement The authors report no conflicts of interest.

Open Access This article is distributed under the terms of the Creative Commons Attribution Noncommercial License which permits any noncommercial use, distribution, and reproduction in any medium, provided the original author(s) and source are credited. 


\section{Appendix: The Frontotemporal Dementia Research in Jutland Association (FReJA)}

Anders Gade, Tove Thusgaard, Memory Disorders Research Group, Copenhagen University Hospital Rigshospitalet, Copenhagen, Denmark. Susanne Gydesen, Psychiatric Centre Ballerup, Copenhagen University Hospital, Ballerup, Denmark. Elisabet Englund, Department of Pathology, Lund University Hospital, Lund, Sweden. This work was undertaken at UCLH/UCL, and was supported by the Department of Health's NIHR Biomedical Research Centres; the Medical Research Council, UK; the National Institute on Aging, National Institutes of Health [grant numbers P30 AG012300 to UTSW, P30 AG13854 to NWU, P50 AG16574 to Mayo Clinic, AG10124 and AG17546 to U. Penn.]; the National Center for Research Resources, National Institutes of Health [grant number UL1RR024982]; the National Institutes of Health [grant number NIH NS65782-01 J]; the Fund for Scientific Research Flanders (FWO-V); the IAP P6/43 network of the Belgian Science Policy Office (BELSPO); the Winspear Family Center for Research on the Neuropathology of Alzheimer Disease and the McCune Foundation.

\section{References}

1. Baker M, Mackenzie IR, Pickering-Brown SM, Gass J, Rademakers R, Lindholm C, Snowden J, Adamson J, Sadovnick AD, Rollinson S, Cannon A, Dwosh E, Neary D, Melquist S, Richardson A, Dickson D, Berger Z, Eriksen J, Robinson T, Zehr C, Dickey CA, Crook R, McGowan E, Mann D, Boeve B, Feldman $\mathrm{H}$, Hutton $\mathrm{M}$ (2006) Mutations in progranulin cause tau-negative frontotemporal dementia linked to chromosome 17. Nature 442:916-919

2. Beck J, Rohrer JD, Campbell T, Isaacs A, Morrison KE, Goodall EF, Warrington EK, Stevens J, Revesz T, Holton J, Al Sarraj S, King A, Scahill R, Warren JD, Fox NC, Rossor MN, Collinge J, Mead S (2008) A distinct clinical, neuropsychological and radiological phenotype is associated with progranulin gene mutations in a large UK series. Brain 131:706-720

3. Cairns NJ, Grossman M, Arnold SE, Burn DJ, Jaros E, Perry RH, Duyckaerts C, Stankoff B, Pillon B, Skullerud K, Cruz-Sanchez FF, Bigio EH, Mackenzie IR, Gearing M, Juncos JL, Glass JD, Yokoo H, Nakazato Y, Mosaheb S, Thorpe JR, Uryu K, Lee VM, Trojanowski JQ (2004) Clinical and neuropathologic variation in neuronal intermediate filament inclusion disease. Neurology 63:1376-1384

4. Cairns NJ, Neumann M, Bigio EH, Holm IE, Troost D, Hatanpaa KJ, Foong C, White CL III, Schneider JA, Kretzschmar HA, Carter D, Taylor-Reinwald L, Paulsmeyer K, Strider J, Gitcho M, Goate AM, Morris JC, Mishra M, Kwong LK, Stieber A, Xu Y, Forman MS, Trojanowski JQ, Lee VM, Mackenzie IR (2007) TDP-43 in familial and sporadic frontotemporal lobar degeneration with ubiquitin inclusions. Am J Pathol 171:227-240

5. Cairns NJ, Uryu K, Bigio EH, Mackenzie IRA, Gearing M, Duyckaerts C, Yokoo H, Nakazato Y, Jaros E, Perry RH, Arnold
SE, Lee VMY, Trojanowski JQ (2004) alpha-Internexin aggregates are abundant in neuronal intermediate filament inclusion disease (NIFID) but rare in other neurodegenerative diseases. Acta Neuropathol 108:213-223

6. Chow TW, Miller BL, Hayashi VN, Geschwind DH (1999) Inheritance of frontotemporal dementia. Arch Neurol 56:817-822

7. Cruts M, Gijselinck I, van der Zee J, Engelborghs S, Wils H, Pirici D, Rademakers R, Vandenberghe R, Dermaut B, Martin JJ, van Duijn C, Peeters K, Sciot R, Santens P, De Pooter T, Mattheijssens M, Van den Broeck M, Cuijt I, Vennekens K, De Deyn PP, Kumar-Singh S, Van Broeckhoven C (2006) Null mutations in progranulin cause ubiquitin-positive frontotemporal dementia linked to chromosome 17q21. Nature 442:920-924

8. Cruts M, Van Broeckhoven C (2008) Loss of progranulin function in frontotemporal lobar degeneration. Trends Genet 24:186194

9. Gass J, Cannon A, Mackenzie IR, Boeve B, Baker M, Adamson J, Crook R, Melquist S, Kuntz K, Petersen R, Josephs K, PickeringBrown SM, Graff-Radford N, Uitti R, Dickson D, Wszolek Z, Gonzalez J, Beach TG, Bigio E, Johnson N, Weintraub S, Mesulam M, White CL III, Woodruff B, Caselli R, Hsiung GY, Feldman H, Knopman D, Hutton M, Rademakers R (2006) Mutations in progranulin are a major cause of ubiquitin-positive frontotemporal lobar degeneration. Hum Mol Genet 15:29883001

10. Guyant-Marechal L, Laquerriere A, Duyckaerts C, Dumanchin C, Bou J, Dugny F, Le Ber I, Frebourg T, Hannequin D, Campion D (2006) Valosin-containing protein gene mutations: clinical and neuropathologic features. Neurology 67:644-651

11. Hasegawa $M$, Arai $T$, Nonaka $T$, Kametani $F$, Yoshida $M$, Hashizume Y, Beach TG, Buratti E, Baralle F, Morita M, Nakano I, Oda T, Tsuchiya K, Akiyama H (2008) Phosphorylated TDP-43 in frontotemporal lobar degeneration and amyotrophic lateral sclerosis. Ann Neurol 64:60-70

12. Hatanpaa KJ, Bigio EH, Cairns NJ, Womack KB, Weintraub S, Morris JC, Foong C, Xiao G, Hladik C, Mantanona TY, White CL III (2008) TAR DNA-binding protein 43 immunohistochemistry reveals extensive neuritic pathology in FTLD-U: a midwest-southwest consortium for FTLD study. J Neuropathol Exp Neurol 67:271-279

13. Holm IE, Englund E, Mackenzie IR, Johannsen P, Isaacs AM (2007) A reassessment of the neuropathology of frontotemporal dementia linked to chromosome 3. J Neuropathol Exp Neurol 66:884-891

14. Holm IE, Isaacs AM, Mackenzie IRA (2009) Absence of FUSimmunoreactive pathology in frontotemporal dementia linked to chromosome 3 (FTD-3) caused by mutation in the CHMP2B gene. Acta Neuropathol 118:719-720

15. Houlden H, Baker M, Adamson J, Grover A, Waring S, Dickson D, Lynch T, Boeve B, Petersen RC, Pickering-Brown S, Owen F, Neary D, Craufurd D, Snowden J, Mann D, Hutton M (1999) Frequency of tau mutations in three series of non-Alzheimer's degenerative dementia. Ann Neurol 46:243-248

16. Hutton M, Lendon CL, Rizzu P, Baker M, Froelich S, Houlden H, Pickering-Brown S, Chakraverty S, Isaacs A, Grover A, Hackett J, Adamson J, Lincoln S, Dickson D, Davies P, Petersen RC, Stevens M, de Graaff E, Wauters E, van Baren J, Hillebrand M, Joosse M, Kwon JM, Nowotny P, Che LK, Norton J, Morris JC, Reed LA, Trojanowski J, Basun H, Lannfelt L, Neystat M, Fahn S, Dark F, Tannenberg T, Dodd PR, Hayward N, Kwok JB, Schofield PR, Andreadis A, Snowden J, Craufurd D, Neary D, Owen F, Oostra BA, Hardy J, Goate A, van Swieten J, Mann D, Lynch T, Heutink P (1998) Association of missense and 5'-splicesite mutations in tau with the inherited dementia FTDP-17. Nature 393:702-705 
17. Ikeda K (2000) Neuropatholl discrepancy between Japanese Pick's disease without Pick bodies and frontal lobe degeneration type of frontotemporal dementia proposed by Lund and Manchester Group. Neuropathology 20:76-82

18. Ishihara K, Araki S, Ihori N, Shiota J, Kawamura M, Nakano I (2006) An autopsy case of frontotemporal dementia with severe dysarthria and motor neuron disease showing numerous basophilic inclusions. Neuropathology 26:447-454

19. Josephs KA, Holton JL, Rossor MN, Braendgaard H, Ozawa T, Fox NC, Petersen RC, Pearl GS, Ganguly M, Rosa P, Laursen H, Parisi JE, Waldemar G, Quinn NP, Dickson DW, Revesz T (2003) Neurofilament inclusion body disease: a new proteinopathy? Brain 126:2291-2303

20. Josephs KA, Holton JL, Rossor MN, Godbolt AK, Ozawa T, Strand K, Khan N, Al-Sarraj S, Revesz T (2004) Frontotemporal lobar degeneration and ubiquitin immunohistochemistry. Neuropathol Appl Neurobiol 30:369-373

21. Josephs KA, Lin WL, Ahmed Z, Stroh DA, Graff-Radford NR, Dickson DW (2008) Frontotemporal lobar degeneration with ubiquitin-positive, but TDP-43-negative inclusions. Acta Neuropathol 116:159-167

22. Knibb JA, Kipps CM, Hodges JR (2006) Frontotemporal dementia. Curr Opin Neurol 19:565-571

23. Kwiatkowski TJ Jr, Bosco DA, Leclerc AL, Tamrazian E, Vanderburg CR, Russ C, Davis A, Gilchrist J, Kasarskis EJ, Munsat T, Valdmanis P, Rouleau GA, Hosler BA, Cortelli P, de Jong PJ, Yoshinaga Y, Haines JL, Pericak-Vance MA, Yan J, Ticozzi N, Siddique T, Kenna-Yasek D, Sapp PC, Horvitz HR, Landers JE, Brown RH Jr (2009) Mutations in the FUS/TLS gene on chromosome 16 cause familial amyotrophic lateral sclerosis. Science 323:1205-1208

24. Lagier-Tourenne C, Cleveland DW (2009) Rethinking ALS: the FUS about TDP-43. Cell 136:1001-1004

25. Lindquist SG, Braedgaard H, Svenstrup K, Isaacs AM, Nielsen JE (2008) Frontotemporal dementia linked to chromosome 3 (FTD3) - current concepts and the detection of a previously unknown branch of the Danish FTD-3 family. Eur J Neurol 15:667-670

26. Lipton AM, White CL III, Bigio EH (2004) Frontotemporal lobar degeneration with motor neuron disease-type inclusions predominates in 76 cases of frontotemporal degeneration. Acta Neuropathol 108:379-385

27. Luty AA, Kwok JB, Thompson EM, Blumbergs P, Brooks WS, Loy CT, Dobson-Stone C, Panegyres PK, Hecker J, Nicholson GA, Halliday GM, Schofield PR (2008) Pedigree with frontotemporal lobar degeneration-motor neuron disease and Tar DNA binding protein-43 positive neuropathology: genetic linkage to chromosome 9. BMC Neurol 8:32

28. Mackenzie IR, Baborie A, Pickering-Brown S, Du PD, Jaros E, Perry RH, Neary D, Snowden JS, Mann DM (2006) Heterogeneity of ubiquitin pathology in frontotemporal lobar degeneration: classification and relation to clinical phenotype. Acta Neuropathol 112:539-549

29. Mackenzie IR, Foti D, Woulfe J, Hurwitz TA (2008) Atypical frontotemporal lobar degeneration with ubiquitin-positive, TDP43-negative neuronal inclusions. Brain 131:1282-1293

30. Mackenzie IR, Neumann M, Bigio EH, Cairns NJ, Alafuzoff I, Kril J, Kovacs GG, Ghetti B, Halliday G, Holm IE, Ince PG, Kamphorst W, Revesz T, Rozemuller AJ, Kumar-Singh S, Akiyama H, Baborie A, Spina S, Dickson DW, Trojanowski JQ, Mann DM (2009) Nomenclature for neuropathologic subtypes of frontotemporal lobar degeneration: consensus recommendations. Acta Neuropathol 117:15-18

31. Mackenzie IR, Neumann M, Bigio EH, Cairns NJ, Alafuzoff I, Kril J, Kovacs GG, Ghetti B, Halliday G, Holm IE, Ince PG, Kamphorst W, Revesz T, Rozemuller AJ, Kumar-Singh S, Akiyama H, Baborie A, Spina S, Dickson DW, Trojanowski JQ,
Mann DM (2010) Nomenclature and nosology for neuropathologic subtypes of frontotemporal lobar degeneration: an update. Acta Neuropathol 119:1-4

32. Mackenzie IR, Shi J, Shaw CL, Duplessis D, Neary D, Snowden JS, Mann DM (2006) Dementia lacking distinctive histology (DLDH) revisited. Acta Neuropathol 112:551-559

33. McKhann GM, Albert MS, Grossman M, Miller B, Dickson D, Trojanowski JQ (2001) Clinical and pathological diagnosis of frontotemporal dementia: report of the Work Group on Frontotemporal Dementia and Pick's Disease. Arch Neurol 58:18031809

34. Munoz DG, Neumann M, Kusaka H, Yokota O, Ishihara K, Terada S, Kuroda S, Mackenzie IR (2009) FUS pathology in basophilic inclusion body disease. Acta Neuropathol 118:617627

35. Munoz-Garcia D, Ludwin SK (1984) Classic and generalized variants of Pick's disease: a clinicopathological, ultrastructural, and immunocytochemical comparative study. Ann Neurol 16:467480

36. Neary D, Snowden JS, Gustafson L, Passant U, Stuss D, Black S, Freedman M, Kertesz A, Robert PH, Albert M, Boone K, Miller BL, Cummings J, Benson DF (1998) Frontotemporal lobar degeneration: a consensus on clinical diagnostic criteria. Neurology 51:1546-1554

37. Neumann M, Rademakers R, Roeber S, Baker M, Kretzschmar HA, Mackenzie IR (2009) A new subtype of frontotemporal lobar degeneration with FUS pathology. Brain 132:2922-2931

38. Neumann M, Roeber S, Kretzschmar HA, Rademakers R, Baker M, Mackenzie IR (2009) Abundant FUS-immunoreactive pathology in neuronal intermediate filament inclusion disease. Acta Neuropathol 118:605-616

39. Neumann M, Sampathu DM, Kwong LK, Truax AC, Micsenyi MC, Chou TT, Bruce J, Schuck T, Grossman M, Clark CM, McCluskey LF, Miller BL, Masliah E, Mackenzie IR, Feldman H, Feiden W, Kretzschmar HA, Trojanowski JQ, Lee VM (2006) Ubiquitinated TDP-43 in frontotemporal lobar degeneration and amyotrophic lateral sclerosis. Science 314:130-133

40. Pirici D, Vandenberghe R, Rademakers R, Dermaut B, Cruts M, Vennekens K, Cuijt I, Lubke U, Ceuterick C, Martin JJ, Van Broeckhoven C, Kumar-Singh S (2006) Characterization of ubiquitinated intraneuronal inclusions in a novel Belgian frontotemporal lobar degeneration family. J Neuropathol Exp Neurol 65:289-301

41. Rademakers R, Cruts M, Van Broeckhoven C (2004) The role of tau (MAPT) in frontotemporal dementia and related tauopathies. Hum Mutat 24:277-295

42. Roeber S, Mackenzie IR, Kretzschmar HA, Neumann M (2008) TDP-43-negative FTLD-U is a significant new clinico-pathological subtype of FTLD. Acta Neuropathol 116:147-157

43. Rohrer JD, Guerreiro R, Vandrovcova J, Uphill J, Reiman D, Beck J, Isaacs AM, Authier A, Ferrari R, Fox NC, Mackenzie IR, Warren JD, de Silva R, Holton J, Revesz T, Hardy J, Mead S, Rossor MN (2009) The heritability and genetics of frontotemporal lobar degeneration. Neurology 73:1451-1456

44. Rosso SM, Donker KL, Baks T, Joosse M, de Koning I, Pijnenburg Y, de Jong D, Dooijes D, Kamphorst W, Ravid R, Niermeijer MF, Verheij F, Kremer HP, Scheltens P, van Duijn CM, Heutink P, van Swieten JC (2003) Frontotemporal dementia in The Netherlands: patient characteristics and prevalence estimates from a population-based study. Brain 126:2016-2022

45. Sampathu DM, Neumann M, Kwong LK, Chou TT, Micsenyi M, Truax A, Bruce J, Grossman M, Trojanowski JQ, Lee VMY (2006) Pathological heterogeneity of frontotemporal lobar degeneration with ubiquitin-positive inclusions delineated by ubiquitin immunohistochemistry and novel monoclonal antibodies. Am J Pathol 169:1343-1352 
46. Seelaar H, Klijnsma KY, de Koning I, van der Lugt A, Chiu WZ, Azmani A, Rozemuller AJ, van Swieten JC (2009) Frequency of ubiquitin and FUS-positive, TDP-43-negative frontotemporal lobar degeneration. J Neurol 257:747-753

47. Seelaar H, Schelhaas HJ, Azmani A, Kusters B, Rosso S, MajoorKrakauer D, de Rijik MC, Rizzu P, ten Brummelhuis M, van Doorn PA, Kamphorst W, Willemsen R, van Swieten JC (2007) TDP-43 pathology in familial frontotemporal dementia and motor neuron disease without Progranulin mutations. Brain 130:13751385

48. Shi J, Shaw CL, Du PD, Richardson AM, Bailey KL, Julien C, Stopford C, Thompson J, Varma A, Craufurd D, Tian J, Pickering-Brown S, Neary D, Snowden JS, Mann DM (2005) Histopathological changes underlying frontotemporal lobar degeneration with clinicopathological correlation. Acta Neuropathol 110:501-512

49. Skibinski G, Parkinson NJ, Brown JM, Chakrabarti L, Lloyd SL, Hummerich H, Nielsen JE, Hodges JR, Spillantini MG, Thusgaard T, Brandner S, Brun A, Rossor MN, Gade A, Johannsen P, Sorensen SA, Gydesen S, Fisher EM, Collinge J (2005) Mutations in the endosomal ESCRTIII-complex subunit CHMP2B in frontotemporal dementia. Nat Genet 37:806-808

50. Snowden JS, Neary D, Mann DM (2002) Frontotemporal dementia. Br J Psychiatry 180:140-143

51. Tsuchiya K, Ishizu H, Nakano I, Kita Y, Sawabe M, Haga C, Kuyama K, Nishinaka T, Oyanagi K, Ikeda K, Kuroda S (2001) Distribution of basal ganglia lesions in generalized variant of Pick's disease: a clinicopathological study of four autopsy cases. Acta Neuropathol 102:441-448

52. Urwin H, Ghazi-Noori S, Collinge J, Isaacs A (2009) The role of CHMP2B in frontotemporal dementia. Biochem Soc Trans 37:208-212
53. van der Zee J, Pirici D, Van Langenhove T, Engelborghs S, Vandenberghe R, Hoffmann M, Pusswald G, Van den Broeck M, Peeters K, Mattheijssens M, Martin JJ, De Deyn PP, Cruts M, Haubenberger D, Kumar-Singh S, Zimprich A, Van Broeckhoven C (2009) Clinical heterogeneity in 3 unrelated families linked to VCP p.Arg159His. Neurology 73:626-632

54. van der Zee J, Urwin H, Engelborghs S, Bruyland M, Vandenberghe R, Dermaut B, De PT, Peeters K, Santens P, De Deyn PP, Fisher EM, Collinge J, Isaacs AM, Van BC (2008) CHMP2B Ctruncating mutations in frontotemporal lobar degeneration are associated with an aberrant endosomal phenotype in vitro. Hum Mol Genet 17:313-322

55. Vance C, Rogelj B, Hortobagyi T, De Vos KJ, Nishimura AL, Sreedharan J, Hu X, Smith B, Ruddy D, Wright P, Ganesalingam J, Williams KL, Tripathi V, Al-Saraj S, Al-Chalabi A, Leigh PN, Blair IP, Nicholson G, de Belleroche J, Gallo JM, Miller CC, Shaw CE (2009) Mutations in FUS, an RNA processing protein, cause familial amyotrophic lateral sclerosis type 6. Science 323:1208-1211

56. Watts GD, Wymer J, Kovach MJ, Mehta SG, Mumm S, Darvish D, Pestronk A, Whyte MP, Kimonis VE (2004) Inclusion body myopathy associated with Paget disease of bone and frontotemporal dementia is caused by mutant valosin-containing protein. Nat Genet 36:377-381

57. Woulfe J, Gray DA, Mackenzie IR (2009) FUS-Immunoreactive Intranuclear Inclusions in Neurodegenerative Disease. Brain Pathol (in press)

58. Yokota O, Tsuchiya K, Terada S, Ishizu H, Uchikado H, Ikeda M, Oyanagi K, Nakano I, Murayama S, Kuroda S, Akiyama H (2008) Basophilic inclusion body disease and neuronal intermediate filament inclusion disease: a comparative clinicopathological study. Acta Neuropathol 115:561-575 